\title{
Hypofractionated proton beam radiotherapy in patients with unresectable liver tumors: multi-institutional prospective results from the Proton Collaborative Group
}

\author{
Jacob S. Parzen ${ }^{1 \dagger}$, William Hartsell ${ }^{2}$, John Chang ${ }^{3}$, Smith Apisarnthanarax ${ }^{4}$, Jason Molitoris ${ }^{5}$, Michael Durci ${ }^{6}$,
} Henry Tsai ${ }^{7}$, James Urbanic ${ }^{8}$, Jonathan Ashman ${ }^{9}$, Carlos Vargas ${ }^{9}$, Craig Stevens ${ }^{1}$ and Peyman Kabolizadeh ${ }^{1}, 10^{*}$

\begin{abstract}
Background: Recent advances in radiotherapy techniques have allowed ablative doses to be safely delivered to inoperable liver tumors. In this setting, proton beam radiotherapy (PBT) provides the means to escalate radiation dose to the target volume while sparing the uninvolved liver. This study evaluated the safety and efficacy of hypofractionated PBT for liver tumors, predominantly hepatocellular carcinoma (HCC) and intrahepatic cholangiocarcinoma (ICC).

Methods: We evaluated the prospective registry of the Proton Collaborative Group for patients undergoing definitive PBT for liver tumors. Demographic, clinicopathologic, toxicity, and dosimetry information were compiled.

Results: To date, 63 patients have been treated at 9 institutions between 2013 and 2019. Thirty (48\%) had HCC and 25 (40\%) had ICC. The median dose and biological equivalent dose (BED) delivered was 58.05 GyE (range 32.5-75) and 80.5 GyE (range 53.6-100), respectively. The median mean liver BED was 13.9 GyE. Three (4.8\%) patients experienced at least one grade $\geq 3$ toxicity. With median follow-up of 5.1 months (range $0.1-40.8$ ), the local control (LC) rate at 1 year was $91.2 \%$ for HCC and $90.9 \%$ for ICC. The 1-year LC was significantly higher (95.7\%) for patients receiving BED greater than $75.2 \mathrm{GyE}$ than for patients receiving BED of $75.2 \mathrm{GyE}$ or lower $(84.6 \%, p=0.029)$. The overall survival rate at 1 year was $65.6 \%$ for HCC and $81.8 \%$ for ICC.
\end{abstract}

Conclusions: Hypofractionated PBT results in excellent LC, sparing of the uninvolved liver, and low toxicity, even in the setting of dose-escalation. Higher dose correlates with improved LC, highlighting the importance of PBT especially in patients with recurrent or bulky disease.

Keywords: Proton therapy, Unresectable liver tumors, Hepatocellular carcinoma, Cholangiocarcinoma

*Correspondence: peymanmcv@gmail.com

† Jacob S. Parzen: Responsible for statistical analyses.

${ }^{10}$ Department of Radiation Oncology, Oakland University William

Beaumont School of Medicine, 3601 W Thirteen Mile Rd, Royal Oak, MI 48073, USA

Full list of author information is available at the end of the article

\begin{abstract}
Introduction
The incidence of liver and intrahepatic bile duct tumors is increasing the most rapidly of any cancer in the United States [1]. Unfortunately, a minority of patients are eligible for curative surgical resection at presentation for either medical or anatomical reasons, leading to a dismal $18 \%$ 5-year overall survival rate [1]. Inoperable patients are often treated with other non-surgical local therapies, such as transarterial chemoembolization, transarterial radioembolization, and radiofrequency ablation.
\end{abstract} original author(s) and the source, provide a link to the Creative Commons licence, and indicate if changes were made. The images or other third party material in this article are included in the article's Creative Commons licence, unless indicated otherwise in a credit line to the material. If material is not included in the article's Creative Commons licence and your intended use is not permitted by statutory regulation or exceeds the permitted use, you will need to obtain permission directly from the copyright holder. To view a copy of this licence, visit http://creativecommons.org/licenses/by/4.0/. The Creative Commons Public Domain Dedication waiver (http://creativeco mmons.org/publicdomain/zero/1.0/) applies to the data made available in this article, unless otherwise stated in a credit line to the data. 
However, not all patients are candidates for these procedures, and eligible patients may not have a durable response to treatment. The role for potentially curative radiation therapy has been expanding considerably in this patient population [2]. With conventional fractionation, most patients experience local progression as the first site of failure after treatment [3]. However, technological advances in radiation treatment planning including fourdimensional respiratory motion management, imageguided radiation therapy, and proton therapy have made hypofractionated and ablative regimens safe and feasible [4-6].

Hepatocellular carcinoma (HCC) and intrahepatic cholangiocarcinoma (ICC) are commonly studied together due to shared clinical management. For HCC, multiple single-arm phase II trials have established the safety and efficacy of hypofractionated ablative radiation treatment [8-10]. Similarly, there have been prospective studies supporting this approach in ICC $[5,10]$. A doseresponse relationship for both clinical entities has been suggested [11, 12], but dose-escalation is ultimately limited by liver tolerance. The risk of radiation-induced liver disease (RILD) is influenced not only by the dose and volume of liver irradiated but also by the patient's underlying liver disease.

Proton beam therapy (PBT) has the potential to improve dose conformity while sparing normal liver when compared to photon-based radiotherapy [13, 14]. In contrast to photon-based therapy, the proton Bragg peak yields a localized high-dose region in the tumor without exit dose. This dosimetric advantage spares a greater volume of uninvolved hepatic parenchyma and allows safer dose escalation in target volumes. Given the importance of proton therapy in treating liver tumors, the ongoing NRG GI-003 is focusing on evaluating the comparative efficacy of protons versus photons in patients with HCC. In this study, we used a multi-institutional prospective registry database to evaluate the safety and efficacy of ablative proton beam therapy for liver tumors, predominantly $\mathrm{HCC}$ and ICC.

\section{Methods and materials}

REG001-09 (NCT01255748) is a prospective, multi-institutional registry of patients undergoing proton therapy at Proton Collaborative Group (PCG) institutions. Written informed consents were obtained from all patients before they were enrolled on the registry.

The registry trial was queried for patients undergoing definitive proton beam radiation therapy for liver tumors. Patients undergoing photon therapy were excluded. Patient, tumor characteristics, radiation treatment details, toxicity, and dosimetric information were all collected.
Patients underwent four-dimensional simulation with intravenous contrast. Immobilization method was per institutional discretion. All patients were treated with pencil beam scanning or passive scattering/uniform scanning. The relative biologic effectiveness (RBE) was set at 1.1 per institutional standard of all participating institutions. The dose unit Gy-equivalent $(\mathrm{GyE})$ was proton dose in Gy multiplied by RBE. Fractionation schemes were at the discretion of participating institutions. Follow-up was institutional. Toxicity was graded using the National Cancer Institute Common Terminology Criteria for Adverse Events (CTCAE) version 4.0. We assumed an $\alpha / \beta=10$ for tumor effect and an $\alpha / \beta=3$ for radiationinduced liver toxicity. The linear-quadratic model was used for biological equivalent dose (BED) calculations.

Local control (LC), overall survival (OS), and progression-free survival (PFS) were calculated starting from the first day of radiation. The OS time of a patient still alive at the time of most recent follow-up was censored. A PFS event was defined as documented local or distant recurrence, or death, whichever was earlier, or otherwise was censored at last follow-up. OS and PFS rates were estimated using the Kaplan-Meier method and the differences between groups were compared with the log-rank test. The risk of local recurrence was estimated using the cumulative incidence function, treating death as a competing risk. Univariate analysis was performed using the Fine-Gray regression model [15]. Statistical analyses were performed using $\mathrm{R}$ version 3.6.2. Statistical significance was set to $P<0.05$.

\section{Results}

Sixty-three patients signed consent forms and were enrolled on the registry trial database. These patients were treated across 9 institutions between 2013 and 2019. The median number of patients treated per institution was 3 (range 1-17). Of the 63 patients, 30 had HCC, 25 had ICC, 4 had carcinoid tumors, 1 had spindle cell carcinoma, 1 had a liver metastasis, and 2 had unknown lesions. Patient characteristics are listed in Table 1. Child-Pugh status and the number of lesions present at the time of radiation were not collected on the registry. Thirty-two patients had smoking histories (51\%), 25 did not $(40 \%)$, and smoking status was unknown for $6(10 \%)$.

\section{Radiation dosing}

Thirteen patients $(21 \%)$ were treated with 5-fraction regimens, $46(73 \%)$ were treated with 15 -fraction regimens, and 4 (6\%) were treated with 25 -fraction regimens. Amongst patients treated with 5 -fraction regimens, the median dose delivered was 40 GyE (range 32.5-50 GyE; $\mathrm{BED}$ range 53.6-100 GyE). Amongst the 15-fraction regimens, the median dose delivered was $58.05 \mathrm{GyE}$ (range 
Table 1 Patient characteristics

\begin{tabular}{|c|c|c|c|}
\hline Characteristic & $\begin{array}{l}\text { All }(n=63) \\
\% \text { (no.) } \\
\text { or median } \\
\text { (range) }\end{array}$ & $\begin{array}{l}\text { HCC }(n=30) \\
\% \text { (no.) } \\
\text { or median } \\
\text { (range) }\end{array}$ & $\begin{array}{l}\text { ICC }(n=25) \\
\% \text { (no.) } \\
\text { or median } \\
\text { (range) }\end{array}$ \\
\hline Age (years) & $69(29-89)$ & $70.5(34-89)$ & $68(29-87)$ \\
\hline \multicolumn{4}{|l|}{ Sex } \\
\hline Male & $52 \%(33)$ & $73 \%(22)$ & $20 \%(5)$ \\
\hline Female & $48 \%(30)$ & $27 \%(8)$ & $80 \%(20)$ \\
\hline \multicolumn{4}{|l|}{ Race/ethnicity } \\
\hline White & $75 \%(47)$ & $73 \%(22)$ & $76 \%(19)$ \\
\hline Black & $5 \%(3)$ & $0 \%(0)$ & $8 \%(2)$ \\
\hline Asian & $8 \%(5)$ & $13 \%(4)$ & $0 \%(0)$ \\
\hline Hispanic & $6 \%(4)$ & $7 \%(2)$ & $8 \%(2)$ \\
\hline Unknown & $6 \%(4)$ & $7 \%(2)$ & $8 \%(2)$ \\
\hline \multicolumn{4}{|l|}{ ECOG } \\
\hline 0 & $41 \%(26)$ & $43 \%(13)$ & $28 \%(7)$ \\
\hline 1 & $43 \%(27)$ & $33 \%(10)$ & $64 \%(16)$ \\
\hline 2 & $8 \%(5)$ & $17 \%(5)$ & $0 \%(0)$ \\
\hline 3 & $2 \%(1)$ & $3 \%(1)$ & $0 \%(0)$ \\
\hline Tumor dimension, cm & $4.4(0.6-17.0)$ & $4.3(1.2-9.4)$ & $5.5(0.6-17)$ \\
\hline \multicolumn{4}{|l|}{ Previous therapy } \\
\hline Surgery & $13 \%(8)$ & $13 \%(4)$ & $12 \%(3)$ \\
\hline TACE/TARE & $30 \%(19)$ & $53 \%(16)$ & $8 \%(2)$ \\
\hline RFA & $6 \%(4)$ & $13 \%(4)$ & $0 \%(0)$ \\
\hline Chemotherapy & $30 \%(19)$ & $10 \%(3)$ & $60 \%(15)$ \\
\hline Radiation therapy & $10 \%(6)$ & $10 \%(3)$ & $12 \%(3)$ \\
\hline None & $40 \%(25)$ & $37 \%(11)$ & $32 \%(8)$ \\
\hline
\end{tabular}

HCC hepatocellular carcinoma, ICC intrahepatic cholangiocarcinoma, TACE transcatheter arterial chemoembolization, TARE transarterial radioembolization, RFA radiofrequency ablation

45-67.5 GyE; BED range 58.5-97.9 GyE). Amongst the 25-fraction regimens, the median dose delivered was 71.1 GyE (range 60.1-75 GyE; BED range 74.5-97.5 GyE). The overall median biological equivalent dose (BED) was 80.5 GyE (range 53.6-100). The median mean dose received by the uninvolved liver (MLD) expressed in biological equivalent dose was $13.9 \mathrm{GyE}$ (range 4.2-31.4). Fifty-two (83\%) had no treatment breaks, and the remaining 11 (17\%) had breaks in treatment but ultimately completed their treatment courses. Seven delays (64\%) were attributed to the machine being down, four delays (27\%) were secondary to personal patient issues not related to treatment toxicity, and one (9\%) was due to the presence of bowel gas prohibiting safe delivery of treatment. One patient had 2 treatment breaks.

\section{Toxicity}

Acute and chronic toxicities are presented in Table 2. The latencies to toxicity ranged from 0-38.3 months. Fifty-one (81\%) of patients experienced at least one radiation-induced toxicity on the registry. The most common toxicities were fatigue $(33 / 63,52 \%)$, radiation dermatitis $(21 / 63,33 \%)$, anorexia $(15 / 63,24 \%)$, and nausea $(13 / 63$, $21 \%)$. Only three patients $(4.8 \%)$ experienced at least one grade $\geq 3$ toxicity. One $\mathrm{HCC}$ patient experienced grade 4 hyperbilirubinemia and grade 3 back pain. One ICC patient experienced grade 3 sinus bradycardia and another ICC patient experienced grade 3 abdominal pain. There were no grade 5 toxicities.

\section{Disease-specific outcomes}

Median follow-up was 5.1 months for the whole cohort (range 0.1-40.8 months). Patients with HCC had a median of 8.2 months follow-up, and their median PFS was 12.6 months (95\% CI lower bound 8.1 months; upper bound not reached). The 1-year PFS rate was $60.3 \%$. The median OS was 16.9 months (95\% CI lower bound 12.1 months; upper bound not reached). The 1-year OS rate was $71.5 \%$ (Fig. 1a). Amongst ICC patients with median of 4.8 months follow-up, the median PFS was 15.6 months (95\% CI lower bound 6.6 months; upper bound not reached). The 1-year PFS rate was $67.3 \%$. The median OS was 20.1 months (95\% CI lower bound 14.7 months; upper bound not reached). The 1-year OS rate was $81.8 \%$. There was no difference in OS $(p=0.2)$ or KPS $(p=0.1)$ between patients with HCC and ICC (Fig. 1a, b). For patients with HCC and ICC, the median OS was 18.2 months (95\% CI lower bound 14.2 months; upper bound not reached) for those patients receiving < 75.2 GyE BED and 16.9 months (95\% CI lower bound 12.1 months; upper bound not reached) for those patients receiving $\geq 75.2 \mathrm{GyE} \operatorname{BED}(p=0.9)$ (Fig. 1c).

Five patients (four HCC and one ICC) experienced local failure within 2 years of follow-up. For patients with HCC and ICC, the 1-year LC rate was 91.1\% (95\% CI $78.4-97.8 \%)$ and the 2-year LC rate was $81.1 \%(95 \%$ CI 63.2-93.8\%) (Fig. 2a). Hence, evaluating the death without local recurrence as a competing factor confirms excellent local control with escalated dose radiotherapy. The 1-year LC rate was $91.2 \%$ for HCC and $90.9 \%$ for ICC (Fig. 2b). On cumulative incidence risk analysis, LC was significantly higher for those patients receiving $\geq 75.2$ GyE BED than for those patients receiving $<75.2 \mathrm{GyE}$ BED (1-year LC 95.7\% versus 84.6\%, $p=0.029$, Fig. 2c). However, there was no difference in overall survival $(p=0.483)$. Factors associated with improved local control are displayed in Table 3. There was a trend towards a statistically significant association with BED (as a continuous variable) and local control $(p=0.057)$. Multivariate analysis was not completed due to the low number of events.

Patterns of failure and death for HCC and ICC patients are displayed in Table 4. Amongst HCC and ICC patients, $59 \%$ and $78 \%$ of patients were alive at last follow-up or 
Table 2 Treatment-related toxicity

\begin{tabular}{|c|c|c|c|}
\hline \multicolumn{4}{|l|}{ Toxicity } \\
\hline CTCAE category & CTCAE term & $\begin{array}{l}\text { Any grade } \\
\% \text { (No.) }\end{array}$ & $\begin{array}{l}\text { Grade 3+ } \\
\% \text { (No.) }\end{array}$ \\
\hline \multirow[t]{2}{*}{ Blood/lymphatic system } & Anemia & $2 \%(1)$ & \\
\hline & Other & $2 \%(1)$ & \\
\hline Cardiac & Sinus bradycardia & $2 \%(1)$ & $2 \%(1)$ \\
\hline \multirow[t]{8}{*}{ Gastrointestinal } & Abdominal pain & $11 \%(7)$ & $2 \%(1)$ \\
\hline & Bloating & $3 \%(2)$ & \\
\hline & Constipaton & $14 \%(9)$ & \\
\hline & Diarrhea & $6 \%(4)$ & \\
\hline & Dysphagia & $6 \%(4)$ & \\
\hline & Nausea & $21 \%(13)$ & \\
\hline & Stomach pain & $3 \%(2)$ & \\
\hline & Vomiting & $2 \%(1)$ & \\
\hline \multirow[t]{2}{*}{ General } & Fatigue & $52 \%(33)$ & \\
\hline & Pain & $19 \%(12)$ & \\
\hline Injury/procedural complications & Radiation Dermatitis & $33 \%(21)$ & \\
\hline \multirow[t]{2}{*}{ Investigations } & Hyperbilirubinemia & $2 \%(1)$ & $2 \%(1)$ \\
\hline & Weight loss & $3 \%(2)$ & \\
\hline Metabolism & Anorexia & $24 \%(15)$ & \\
\hline \multirow[t]{2}{*}{ Musculoskeletal } & Back pain & $6 \%(4)$ & $2 \%(1)$ \\
\hline & Bone pain & $3 \%(2)$ & \\
\hline \multirow[t]{2}{*}{ Respiratory } & Cough & $2 \%(1)$ & \\
\hline & Dyspnea & $6 \%(4)$ & \\
\hline Skin & Hyperpigmentation & $3 \%(2)$ & \\
\hline
\end{tabular}

CTCAE common terminology criteria for adverse events (version 4)

had expired from an unrelated cause to their cancer, respectively. All isolated local failures were without distant failure in both groups.

\section{Discussion}

In this prospective registry of patients undergoing definitive proton therapy for liver tumors, we demonstrate excellent local control with low rates of toxicity. Our rates of local control are comparable to hypofractionated historical series [16-18]. In the absence of phase III data, this adds to the growing body of literature validating this approach and making a compelling case that it should be placed alongside other liver-directed therapies as standard-of-care in patients who are not operable candidates.

By virtue of the Bragg peak, proton radiotherapy offers a distinct dosimetric advantage when compared to photon radiotherapy. An earlier study through Loma Linda, treated 34 patients with HCC to $63 \mathrm{GyE}$ in 15 fractions, reporting a 2-year LC of 75\% [19]. Importantly, there were no cases of RILD. Other studies have corroborated low rates of RILD in patients receiving proton therapy when compared to photon therapy [20, 21], allowing for treatment of large lesions beyond $6 \mathrm{~cm}$ without any significant toxcities [22]. A recent retrospective comparison of proton and photon ablative radiotherapy in patients with unresectable HCC demonstrated an overall survival benefit in patients receiving proton therapy despite no difference in locoregional control [23]. The survival benefit was rather attributed to an increased risk of non-classic RILD, defined as an increase in the baseline Child-Pugh score of $\geq 2$ at 3 months posttreatment, in patients receiving photon-based radiotherapy. Through elimination of the low-dose bath associated with photon therapy, there is relative protection of normal liver parenchyma while still delivering ablative doses to the area of interest, which may have improved clinical outcomes.

Our study builds upon previous prospective experiences treating inoperable $\mathrm{HCC}$ and ICC. Hong et al. conducted a single-arm phase II study treating patients with HCC and ICC to $67.5 \mathrm{GyE}$ in 15 fractions for peripheral tumors and 58.05 Gy in 15 fractions for central tumors with proton beam radiotherapy at three institutions [10]. With median follow-up of 19.5 months, they reported 2-year LC of $94.8 \%$ for HCC and $94.1 \%$ for ICC. The rate of grade 3 toxicity was 


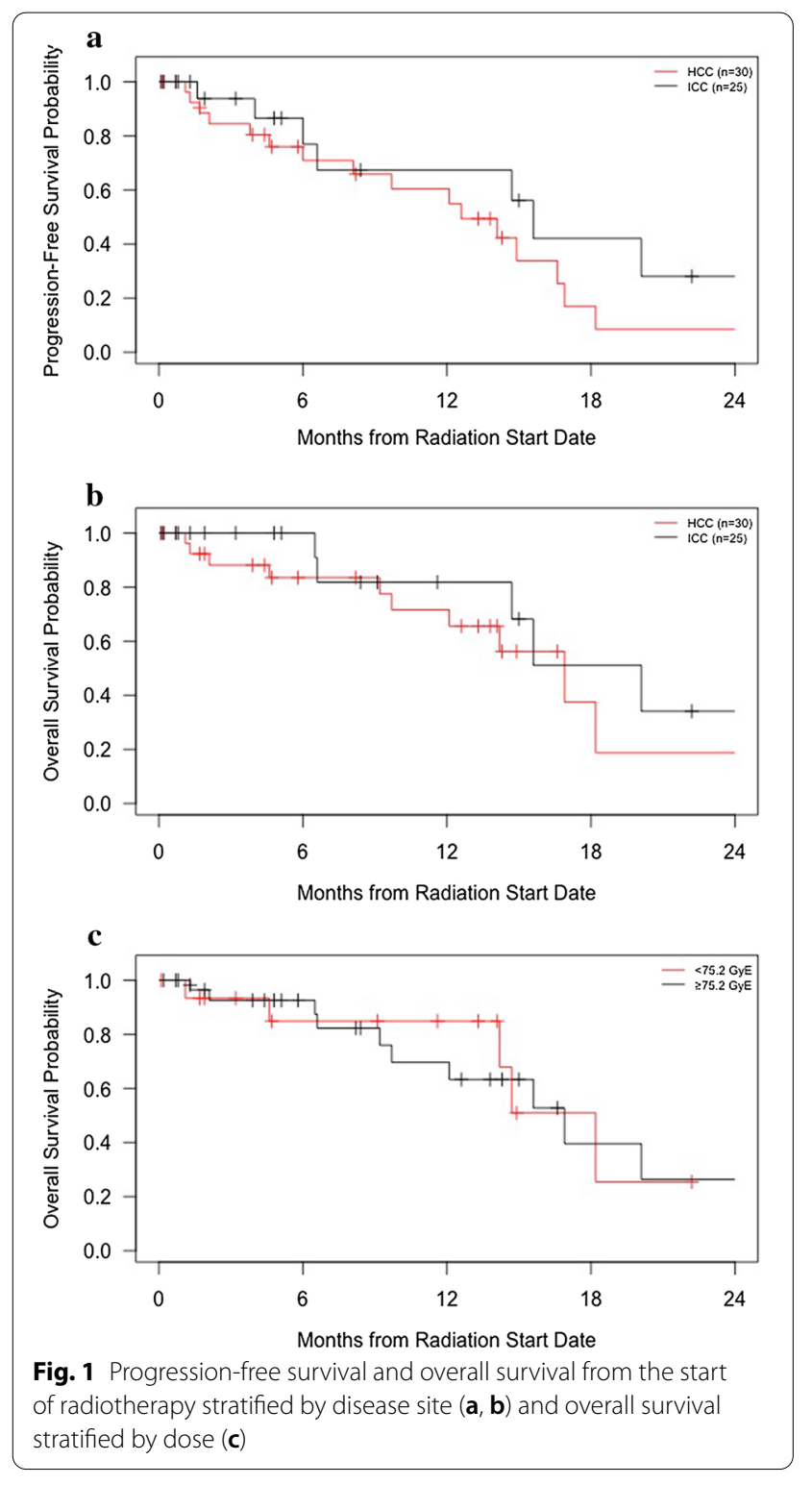

$4.8 \%$. Though all patients on that trial were treated with 15 fractions, the median BED of 80.4 GyE was nearly identical to our experience. Importantly, the 5 fraction patients in our experience do not fare worse from a local control standpoint, supporting extreme hypofractionation as long as sufficient BED is administered. In another similar experience at the Princess Margaret Hospital, 102 patients with HCC were treated on a phase I/II trial from 24 to 54 Gy in 6 fractions with photon radiotherapy [8]. They reported a 1 -year LC rate of $87 \%$. However, the rate of grade $\geq 3$ toxicity was $30 \%$, including 7 cases of grade 5 toxicity.

The differences in toxicities are likely multifactorial. First, the average sum of all liver lesions on the Princess
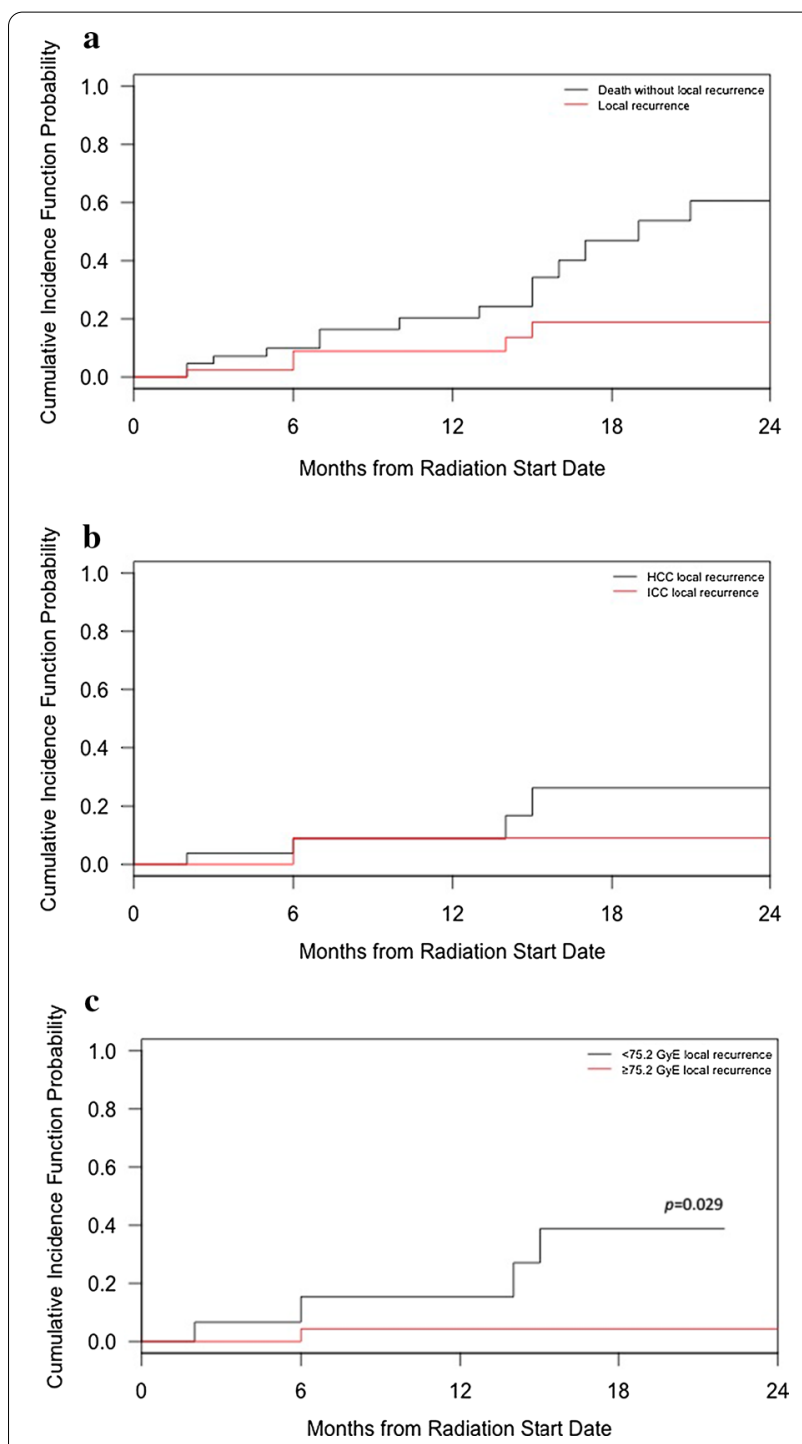

Fig. 2 Cumulative incidence function for local recurrence for all patients (a); by disease type (b); and by radiation dose (c)

Table 3 Univariate analysis for local control

\begin{tabular}{lllll}
\hline Variable & Level & HR & $\mathbf{9 5 \% ~ C l}$ & $\boldsymbol{P}$ \\
\hline Age & & 1.02 & $0.97-1.08$ & 0.35 \\
ECOG & $1-3 \vee 0$ & 2.50 & $0.29-21.80$ & 0.41 \\
Prior treatment & Yes vs. No & 0.53 & $0.10-2.81$ & 0.45 \\
Tumor size (cm) & & 0.87 & $0.65-1.17$ & 0.36 \\
Fractionation & $15 / 25$ vs. 5 & 0.39 & $0.07-1.99$ & 0.26 \\
BED, GyE \pm & & 0.97 & $0.93-1.00$ & 0.057 \\
\hline
\end{tabular}

ECOG Eastern Cooperative Oncology Group performance status, BED biological equivalent dose, $H R$ hazard ratio, GyE Gy equivalent

$\pm B E D$ considered as a continuous variable. The HR represents the effect of an increase of $1 \mathrm{GyE}$ 
Table 4 Patterns of failure

\begin{tabular}{lccc}
\hline PFS Status & $\begin{array}{l}\text { All }(\mathbf{n = 6 3 )} \\
\%(\mathbf{N o .})\end{array}$ & $\begin{array}{l}\text { HCC (n=30) } \\
\%(\mathbf{N o .})\end{array}$ & $\begin{array}{l}\text { ICC (n=25) } \\
\%(\mathbf{N o .})\end{array}$ \\
\hline Alive, no progression & $57 \%(36)$ & $43 \%(13)$ & $68 \%(17)$ \\
Distant metastases & $17 \%(11)$ & $23 \%(7)$ & $12 \%(3)$ \\
Local failure and distant metatases & $0 \%(0)$ & $0 \%(0)$ & $0 \%(0)$ \\
Isolated local failure & $8 \%(5)$ & $13 \%(4)$ & $4 \%(1)$ \\
Dead of this disease, no progression & $3 \%(2)$ & $3 \%(1)$ & $4 \%(1)$ \\
Dead of other causes, no progression & $14 \%(9)$ & $16 \%(5)$ & $10 \%(3)$ \\
\hline
\end{tabular}

PFS progression-free survival, HCC hepatocellular carcinoma, ICC intrahepatic cholangiocarcinoma

Margaret study was $9.9 \mathrm{~cm}$, compared to $5.8 \mathrm{~cm}$ on the Hong et al. study and $4.4 \mathrm{~cm}$ on our study. Caution must be taken when treating very large tumors with extreme hypofractionation. The second and more intriguing possibility is that proton therapy improves toxicity profiles by limiting dose to the uninvolved liver. Using the linear-quadratic model, the median MLD in BED was 13.9 GyE amongst our patients, versus 27.4 GyE on the Hong et al. trial and $30.0 \mathrm{GyE}$ in the Princess Margaret experience. We acknowledge that the tumors on this registry were smaller than the other studies, which would partially account for the difference. It is also likely that the liver-sparing afforded by proton therapy results in lower dose to normal liver which in turn lowers the deleterious effects on liver reserve. The low rates of grade $\geq 3$ toxicity on both the Hong et al. and current study corroborate the importance of liver sparing. As previously mentioned, this is important because lowering the rates of treatment-related liver decompensation may improve clinical outcomes [24]. While the Princess Margaret experience did also raise concerns about extreme hypofractionation from a toxicity standpoint, this was not found in our patients undergoing a 5-fraction schedule, suggesting this approach is safe and feasible in appropriately-selected patients.

The current study also corroborates previous findings that there exists a dose-response relationship with respect to tumor control. This did not translate into an overall survival benefit most likely due to short follow-up, and possibly competing risks of new lesions, metastatic disease and liver failure. This is still of critical importance given the first site of progression after radiation therapy is predominantly local [3]. The early University of Michigan experience, on which patients with primary liver tumors or metastases were treated to a median dose of 58.5 Gy in 1.5 Gy twice daily fractions, demonstrated a median survival of 16.4 months in patients treated with at least 70 Gy (BED 80.5 Gy), compared to 11.6 months in patients treated with lower dose [25]. Early data from the Hong et al. phase II trial also suggested a local control and survival benefit with increasing BED (per NRG-GI 003 protocol). More recently, a retrospective experience with inoperative ICC, on which patients were treated to a median BED of 80.5 Gy with both conventional fractionation and hypofractionation, the 3-year LC for patients receiving BED greater than 80.5 Gy was $73 \%$ versus $38 \%$ for those receiving less, and BED as a continuous variable significantly affected both LC and OS [12]. An important criticism of that study is that a large subset of patients were treated with 50.4 Gy in 28 fractions, which is not a radio-ablative regimen. Our study establishes a dose cut-off that is even lower at 75.2 GyE, but there was only a trend towards improvement in LC when BED was evaluated as a continuous variable. The lower threshold established herein could be explained in part by the uncertainly regarding an assumed RBE factor of $1.1[26]$ as is the convention in the participating institutions. However, other studies evaluating proton therapy have established BED cut-offs as high as 90 GyE [11].

Despite the above, proton therapy as a treatment modality remains somewhat controversial given its cost and lack of level I evidence for overall survival, thus prompting the ongoing phase III NRG trial randomizing patients to protons versus photons in patients with HCC [6]. Strengths of the current study include its prospective registry nature and multidisciplinary contributions, affording reasonable sample size for this relatively rare disease entity. Conversely, a notable weakness is the lack of HCC/ICC-specific data included in the registry, including but not limited to Child-Pugh scoring, the presence of tumor vascular thrombosis, the presence of multiple tumors, and more detailed plan information such as volume of liver irradiated. In addition, the relatively limited follow-up time in some patients likely biased patterns of failure results. In addition, due to the disparity in follow-up between the HCC and ICC patients, any differences between the groups reported herein should be interpreted with extreme caution.

In conclusion, hypofractionated ablative proton therapy is safe and efficacious in the treatment of primary liver 
tumors. We have reaffirmed a dose-response relationship and highlighted the importance of dose-escalation in local control. Inasmuch as it is possible while respecting critical dose constraints, clinicians should attempt to deliver a biological equivalent dose of at least $75.2 \mathrm{GyE}$ to unresectable liver tumors when the intent is ablation. The marginal clinical benefit of liver-sparing proton therapy is currently being investigated in a phase III trial.

\section{Acknowledgements}

Not applicable.

\section{Authors' contributions}

JSP contributed to project conception, design of the work, acquisition/ analysis/interpretation of data, and drafted and substantively revised the completed manuscript. WH substantively revised the completed manuscript. JC substantively revised the completed manuscript. SA substantively revised the completed manuscript. JM substantively revised the completed manuscript. MD substantively revised the completed manuscript. HS substantively revised the completed manuscript. JU substantively revised the completed manuscript. JA substantively revised the completed manuscript. CV substantively revised the completed manuscript. CS substantively revised the completed manuscript. PK contributed to project conception, design of the work, acquisition/analysis/interpretation of data, and drafted and substantively revised the completed manuscript. All authors read and approved the final manuscript.

\section{Funding}

The authors report no funding source for the research described herein.

\section{Availability of data and materials}

The datasets generated and analyzed during the current study are not publically available but are available from the corresponding author on reasonable request.

\section{Ethics approval and consent to participate}

This study was approved by the institutional review board of all participating institutions.

\section{Consent for publication}

Not applicable.

\section{Competing interests}

The authors report no proprietary or commercial interest in any product mentioned or concept discussed in this article.

\section{Author details \\ ${ }^{1}$ Beaumont Proton Therapy Center, Royal Oak, MI, USA. ${ }^{2}$ Northwestern Medicine Chicago Proton Center, Warrenville, IL, USA. ${ }^{3}$ Oklahoma Proton Center, Oklahoma City, OK, USA. ${ }^{4}$ Seattle Cancer Care Alliance Proton Therapy Center, Seattle, WA, USA. ${ }^{5}$ Maryland Proton Treatment Center, Baltimore, MD, USA. ${ }^{6}$ Willis-Knighton Cancer Center, Shreveport, LA, USA. ${ }^{7}$ Princeton ProCure Proton Therapy Center, Kendall Park, NJ, USA. ${ }^{8}$ California Protons Therapy Center, San Diego, CA, USA. ${ }^{9}$ Mayo Clinic, Phoenix, AZ, USA. ${ }^{10}$ Department of Radiation Oncology, Oakland University William Beaumont School of Medi- cine, 3601 W Thirteen Mile Rd, Royal Oak, Ml 48073, USA.}

Received: 1 September 2020 Accepted: 29 October 2020

Published online: 04 November 2020

\section{References}

1. Siegel RL, Miller KD, Jemal A. Cancer statistics, 2020. CA Cancer J Clin. 2020;70(1):7-30.

2. Shinohara ET, Mitra N, Guo M, Metz JM. Radiation therapy is associated with improved survival in the adjuvant and definitive treatment of intrahepatic cholangiocarcinoma. Int J Radiat Oncol Biol Phys. 2008;72(5):1495-501.

3. Crane $\mathrm{CH}$, Macdonald KO, Vauthey JN, et al. Limitations of conventional doses of chemoradiation for unresectable biliary cancer. Int J Radiat Oncol Biol Phys. 2002;53(4):969-74.

4. Eccles C, Brock KK, Bissonnette JP, Hawkins M, Dawson LA. Reproducibility of liver position using active breathing coordinator for liver cancer radiotherapy. Int J Radiat Oncol Biol Phys. 2006;64(3):751-9.

5. Tse RV, Hawkins M, Lockwood G, et al. Phase I study of individualized stereotactic body radiotherapy for hepatocellular carcinoma and intrahepatic cholangiocarcinoma. J Clin Oncol. 2008;26(4):657-64.

6. Crane $\mathrm{CH}$, Koay EJ. Solutions that enable ablative radiotherapy for large liver tumors: fractionated dose painting, simultaneous integrated protection, motion management, and computed tomography image guidance. Cancer. 2016;122(13):1974-86.

7. Valle J, Wasan $\mathrm{H}$, Palmer DH, et al. Cisplatin plus gemcitabine versus gemcitabine for biliary tract cancer. N Engl J Med. 2010;362(14):1273-81.

8. Bujold A, Massey CA, Kim JJ, et al. Sequential phase I and II trials of stereotactic body radiotherapy for locally advanced hepatocellular carcinoma. J Clin Oncol. 2013;31(13):1631-9.

9. Bush DA, Kayali Z, Grove R, Slater JD. The safety and efficacy of high-dose proton beam radiotherapy for hepatocellular carcinoma: a phase 2 prospective trial. Cancer. 2011;117(13):3053-9.

10. Hong TS, Wo JY, Yeap BY, et al. Multi-Institutional phase II study of highdose hypofractionated proton beam therapy in patients with localized, unresectable hepatocellular carcinoma and intrahepatic cholangiocarcinoma. J Clin Oncol. 2016;34(5):460-8.

11. Chadha AS, Gunther JR, Hsieh CE, et al. Proton beam therapy outcomes for localized unresectable hepatocellular carcinoma. Radiother Oncol. 2019;133:54-61.

12. Tao R, Krishnan $\mathrm{S}$, Bhosale PR, et al. Ablative radiotherapy doses lead to a substantial prolongation of survival in patients with inoperable intrahepatic cholangiocarcinoma: a retrospective dose response analysis. J Clin Oncol. 2016;34(3):219-26.

13. Skinner HD, Hong TS, Krishnan S. Charged-particle therapy for hepatocellular carcinoma. Semin Radiat Oncol. 2011;21(4):278-86.

14. Wang $X$, Krishnan S, Zhang $X$, et al. Proton radiotherapy for liver tumors: dosimetric advantages over photon plans. Med Dosim. 2008;33(4):259-67.

15. Scrucca L, Santucci A, Aversa F. Regression modeling of competing risk using R: an in depth guide for clinicians. Bone Marrow Transplant. 2010;45(9):1388-95.

16. Mendez Romero A, Wunderink W, Hussain SM, et al. Stereotactic body radiation therapy for primary and metastatic liver tumors: a single institution phase i-ii study. Acta Oncol. 2006;45(7):831-7.

17. Chiba T, Tokuuye K, Matsuzaki Y, et al. Proton beam therapy for hepatocellular carcinoma: a retrospective review of 162 patients. Clin Cancer Res. 2005;11(10):3799-805.

18. Herfarth KK, Debus J, Lohr F, et al. Stereotactic single-dose radiation therapy of liver tumors: results of a phase I/II trial. J Clin Oncol. 2001;19(1):164-70

19. Bush DA, Hillebrand DJ, Slater JM, Slater JD. High-dose proton beam radiotherapy of hepatocellular carcinoma: preliminary results of a phase II trial. Gastroenterology. 2004;127(5 Suppl 1):S189-193.

20. Toramatsu C, Katoh N, Shimizu S, et al. What is the appropriate size criterion for proton radiotherapy for hepatocellular carcinoma? A dosimetric comparison of spot-scanning proton therapy versus intensity-modulated radiation therapy. Radiat Oncol. 2013;8:48.

21. Petersen JB, Lassen Y, Hansen AT, Muren LP, Grau C, Hoyer M. Normal liver tissue sparing by intensity-modulated proton stereotactic body radiotherapy for solitary liver tumours. Acta Oncol. 2011;50(6):823-8.

22. Hong TS, Wo JY, Borger DR, et al. Phase II study of proton-based stereotactic body radiation therapy for liver metastases: importance of tumor genotype. J Natl Cancer Inst. 2017. https://doi.org/10.1093/jnci/djx031.

23. Sanford NN, Pursley J, Noe B, et al. Protons versus photons for unresectable hepatocellular carcinoma: liver decompensation and overall survival. Int J Radiat Oncol Biol Phys. 2019;105(1):64-72.

24. Son $\mathrm{SH}$, Jang HS, Jo IY, et al. Significance of an increase in the Child-Pugh score after radiotherapy in patients with unresectable hepatocellular carcinoma. Radiat Oncol. 2014;9:101. 
25. Dawson LA, McGinn CJ, Normolle D, et al. Escalated focal liver radiation and concurrent hepatic artery fluorodeoxyuridine for unresectable intrahepatic malignancies. J Clin Oncol. 2000;18(11):2210-8.

26. Luhr A, von Neubeck C, Krause M, Troost EGC. Relative biological effectiveness in proton beam therapy — current knowledge and future challenges. Clin TransI Radiat Oncol. 2018;9:35-41.

\section{Publisher's Note}

Springer Nature remains neutral with regard to jurisdictional claims in published maps and institutional affiliations.
Ready to submit your research? Choose BMC and benefit from:

- fast, convenient online submission

- thorough peer review by experienced researchers in your field

- rapid publication on acceptance

- support for research data, including large and complex data types

- gold Open Access which fosters wider collaboration and increased citations

- maximum visibility for your research: over $100 \mathrm{M}$ website views per year

At BMC, research is always in progress.

Learn more biomedcentral.com/submissions 